\title{
Spatial Analysis of the Urban System in Guangdong Province of South China Using Population and Economic Indicators
}

\author{
J. Shen \\ Department of Geography and Resource Management, The Chinese University of Hong Kong, Shatin, N.T., Hong Kong
}

\begin{abstract}
Much advance has been made in the study of the new urbanization process in post reform China. But the resulting urban system in Guangdong province has not been thoroughly analyzed creating a knowledge gap between the new urbanization process and the new urban system. This paper attempts to reveal the emerging urban system hierarchy in the 1990s in Guangdong province under socialist market economy using rank-size distribution as a yardstick. As there was substantial discrepancy among the rank-size distributions of cities in terms of population and economic indicators especially due to the existence of "temporary population" and the policy of "designating a whole county as a city", the urban system in Guangdong province was analyzed using demographic and economic indicators. The significant role of economic development in urban growth was also identified through cross-sectional comparison and correlation analysis of time-series data on economic and urban indicators.
\end{abstract}

Keywords: Urban system, city-size distribution, urban development, China.

\section{INTRODUCTION}

China has entered a new age of rapid urbanization since the early 1980 s with liberal economic and migration policies $[1,2]$. Some interesting studies have focused on the urban system of China as a whole [3-10]. Economic development and urbanization is perhaps most significant in Guangdong province which is located at the south gate of the country, adjacent to Hong Kong and Macau. It had an area of 0.18 million square kilometers and a population of 71.4 million in 1998. By any means, Guangdong is like a medium-sized country. Thus the urban system in the province has been analyzed by some early studies in a fashion of national urban system [11, 12].

Before the introduction of reform and open policy in 1978, Guangdong received little investment for industrial development as the province was not a key region of national construction. The urbanization process was also slow. From 1949 to 1978 , the average annual growth rate of urban population in the province was only $1.61 \%$, much lower than the national average of $1.72 \%$. Since 1978 , Guangdong has entered a new stage of rapid economic development. Its urban population increased from 10.60 million in 1980 to 24.11 million in 1990 and 48.29 million in 2000 . The average annual growth rate of urban population was $8.79 \%$ in the period 1980-2000 [2].

In Guangdong province, development and urbanization are most advanced in its Pearl River Delta (PRD) region [13, 14]. Earlier studies have focused on the impact of various forces such as economic reforms, open door policy and foreign investment on the urbanization in the region [15-22]. The new regime of socialist market economy officially adopted in 1994 has significant impact on the urbanization

*Address correspondence to this author at the Department of Geography and Resource Management, The Chinese University of Hong Kong, Shatin, N.T., Hong Kong; E-mail: jianfa@ @uhk.edu.hk process and the urban system in the Guangdong province. The notions of "urbanization from below", "rural urbanization", "Desakota (a combination of two Indonesian words: desa for village, kota for town) model of urbanization" and "dual track urbanization" have been adopted to characterize the new urbanization process in the post reform period [20, 23-25]. But with a few exceptions [11, 12], the urban system of the province has been rarely studied. Earlier studies usually considered urban population as the single indicator of city size. While population based urban system studies have their own merits, more and more urban studies have shifted to the use of economic indicators in identifying the competitiveness and status of a city in the urban system [26, 27].

In the case of China, population migration has been under the control of a sophisticated household registration (hukou) system. A change in the place of hukou essentially for permanent migration needs government approval. Economic reforms and the introduction of socialist market economy have increased population mobility dramatically but most rural migrants in cities are only registered as temporary population [28]. There is substantial discrepancy in the city ranks in terms of population and economic indicators due to the hukou system and the way new county-level cities are designated.

It is clear that much advance has been made in the study of new urbanization process in the post reform China. But the resulting urban system in Guangdong province has not been thoroughly analyzed creating a knowledge gap between the new urbanization process and the new urban system. The main purpose of the paper is to reveal the emerging urban system hierarchy in Guangdong province using rank-size distribution as a yardstick. The differences in the urban hierarchy based on various population and economic indicators in Guangdong province will be identified and explained. The role of economic development in the urban growth of the province will be analyzed using both cross-sectional and time-series data. 
The rest of the paper is organized as follows. The first section examines the nature of urbanization process unfolding under socialist market economy. The next section focuses on the definition of city size, data and methodology. Section three conducts a detailed analysis of differentials in the rank-size distribution of the urban system in Guangdong using population and economic indicators and section four examines the role of economic development in the growth of cities in Guangdong. Section six deals with conclusions of the paper.

\section{EXPANDING URBANIZATION UNDER THE SO- CIALIST MARKET ECONOMY IN POST REFORM CHINA}

Developed countries have achieved a high level of urbanization and therefore a mature urbanization process which focuses on inter-city dynamics instead of urban expansion is occurring. On the other hand, developing countries are largely in a stage of expanding urbanization where industrialization and economic development are driving urban growth in terms of both the urban population and builtup area [29-31]. The rank-size distributions of the urban system in more developed countries (MDCs) and less developed countries (LDCs) were found to be different. Puga attempted to explain the seemingly different pattern and size of urban agglomeration between MDCs and LDCs using a two-region general equilibrium model based on increasing returns to scales [32]. He explained that European countries developed balanced systems of cities in the $19^{\text {th }}$ century when the costs of spatial interaction were higher, economies of scale were weaker and the pool of agricultural workers available to the urban sector was smaller than in LDCs today.

Urbanization in China has been a fascinating topic due to its unique political-social system and the changing state policy on urbanization $[1,3,33,34]$. Fan challenged the conclusions based on the Western countries that urban growth is primarily a function of economic factors such as the scale and agglomeration economies and the level of economic development [7]. She argued that institutional factors are more important than economic factors of urban growth in China. Earlier studies have also revealed new processes of urbanization which are unfolding under new institutional setting of the post reform China. For example, a new form of urbanization has been identified and named "urbanization from below" [23] or "rural urbanization" [24] which refers to the development of small towns driven by rural industrialization such as TVEs (township and villages enterprises) instead of top-down state investment. Lin questioned the arbitrary distinction of urban and rural areas [20]. Asian model of urbanization, conceptualized as desakota by McGee [35], was considered as more appropriate to describe the urbanization process in the PRD region. More recently, Shen et al. argued that dual-track urbanization has been going on in the post-reform China and that both the state sponsored urbanization (the growth of non-agricultural population) and spontaneous urbanization (TVE-based rural urbanization and temporary population) have been significant in PRD [25].

In pre-reform China, a policy of industrialization with limited urbanization prevailed and the growth of large cities was controlled. Generally, this policy was successful for the country as a whole, producing under-urbanization and a bal- anced urban system in the country. There was no primate city in the country as a whole. However, the case of Guangdong was an exception to the national norm. The regional urban system was dominated by Guangzhou due to an inadequate development of intermediate- and small-sized cities and over concentration of the provincial investment and industries in the provincial capital. There were only nine cities in the province by 1978, namely Guangzhou, Foshan, Jiangmen, Huizhou, Zhaoqing, Shantou, Zhanjiang, Shaoquan and Maoming.

The most significant change took place in 1978 when economic reforms were introduced in China. A new prourban regime has emerged under the socialist market economy [36]. Urbanization now has been accepted as a positive process conducive to the country's modernization and development. Tight control on migration has been relaxed and the population mobility has reached the highest level in China [28].

Although the government policy towards urbanization was more liberal, it is interesting to note that the policy controlling the growth of large cities was further consolidated by stipulation the following in urban planning law in the reform era: controlling the size of large cities and rationally developing intermediate- and small-sized cities [7, 10]. Small cities and towns, considered as economic centers in their hinterland, were generally encouraged to develop rapidly under the new pro-urban regime [23]. Fan found that deconcentration of population among various cities in the urban system of China took place due to its vertical and horizontal expansion [7]. As shown in this paper, decentralized urbanization has also taken place in Guangdong in the post-reform period.

Development of the urban system in Guangdong has much to do with the uneven regional development since 1978. In 1994, China formally declared to adopt a socialist market system and previous constraints on private economy have been gradually removed since then [37, 38]. Guangdong province has been a leader in the economic reform and economic development in China since 1978 [39, 40]. Previous research found that a regional polarization process towards the core PRD region has occurred [38]. Three key forces re-shaping the spatial development in China and in Guangdong province in particular are the foreign direct investment (FDI), migration and the bottom up approach especially the role of local government.

In the process of economic reforms, centrally planning system has gradually been replaced by the market mechanisms in China. The Chinese economy has decentralized steadily with increasing power of local governments. Such changes have most important impacts on areas/cities traditionally with a small sector of state owned enterprises (SOEs) in the pre-reform period such as Guangdong. Local capital accumulation and local investment have become very important in regional development. State investment plays a decreasing role in local investment. Thus it can be expected that the development in Guangzhou, the primate city in the pre-reform era, will be relatively slower than other cities.

As mentioned before, population migration has been under the control of a hukou system. Since the early 1980s, migration policy has been relaxed gradually so that many rural people could migrate to cities for employment and 
business. But the national and regional labor markets are not operating freely. Most rural migrants were only allowed to register as "temporary population" in destination cities. For example, there was a temporary population of over 10 million in Guangdong in 1997 [28]. In some cities such as Shenzhen, the size of temporary population was even greater than the local population with full household registration. The temporary population has significant impact on the population size and economic strength of a city as well as the spatial urban system $[25,41]$.

Foreign direct investment is often regarded as another key force of regional development in Guangdong. Many local governments in Guangdong have special incentives to attract investment from Hong Kong, Macau, Taiwan and foreign countries [42]. The urbanization induced by foreign investment has been conceptualized as exo-urbanisation [19]. Here, the geographical location comes into play with FDI. Because of the closeness between Hong Kong and Guangdong, about half of the total investment from Hong Kong to mainland China landed in Guangdong. PRD region especially Shenzhen city located to the north of Hong Kong has attracted large amount of foreign investment. Previous studies have also shown that domestic investment complements with foreign investment and both of them were concentrated in PRD [40]. These institutional, migration and economic forces will have important implications to the pace of urbanization, the concentration and deconcentration of population and economies in the urban system and the discrepancy in the distribution of population and economic indicators among various cities.

Due to significant development taking place at local level in the rural townships and counties outside major cities such as Guangzhou, many counties have been qualified for city status and have been designated as cities after substantial industrial/economic development. In the period 1978-1998, the number of cities in Guangdong increased from 9 to 54. A new urban system is rapidly emerging in Guangdong province which is the focus of this paper. But one problem caused by the policy of "designating a whole county as a city" is that a varying and high proportion of agricultural/rural population has been included within the city boundaries $[1,43,44]$. There have been keen discussions on the proper definition of urban population in China [45]. The approach of this paper is to examine several population and economic indicators in the spatial analysis of the urban system rather than relying on one single definition of urban population as the size of a city.

\section{DEFINITION OF CITY-SIZE, DATA AND METHOD- OLOGY}

A popular approach in the study of urban system is the examination of rank-size distribution of the population of various cities within a national or regional urban system $[6$, 46]. The population size of a city is used as a surrogate of the role of the city in the national or regional economy. Numerous studies have been conducted to verify and quest for causal explanation for the existence of rank-size relation or urban hierarchy [47-50]. Urban systems which conform to rank-size distribution are considered to have a more even and sometimes more perfect distribution of population than the case of primate city, representing a more advanced development stage of urban systems $[5,9,11]$. The use and concept of city-size distribution has been criticized earlier. Sheppard argued that the theoretical justifications for the rank-size distribution as a desirable urban system were weak [51]. Some recent theoretical simulation studies using generalequilibrium economic approach provided much firm economic foundations for the existence of the rank-size relationship in urban systems [52].

Nevertheless, the rank-size distribution of urban population has also been used as a yardstick to measure the degree of evenness of the distribution of urban population in an urban system, especially in comparison with an urban system dominated by a primate city [10]. Thus although there are still debates about the validity of rank-size distribution as a perfect urban system, it is still a sensible benchmark to assess the even or uneven distribution of urban population in an urban system.

In many empirical studies of rank-size distribution of cities in an urban system, population size of a city is often considered as the key variable. In the theoretical studies mentioned above, real wages are assumed to be the same in all cities in the equilibrium status thus population size would be an adequate surrogate of the role of cities and economic size in an urban system [52]. However, a real urban system is unlikely in a state of equilibrium and thus there are likely to have substantial discrepancy between the rank-size distribution of population and the rank-size distribution of economic indicators. Indeed, population size is considered not very relevant in the study of world cities [53]. More and more urban studies have shifted to use economic indicators, number of TNC (transnational companies) headquarters, airtraffic flows, intercity interactions to identify the competitiveness and status (such as world city or global city) of a city in the urban system $[26,27]$ although urban system studies focused on population size have their own merit especially in the understanding of population dynamics.

In the case of cities in Guangdong, there are significant differences in GDP per capita and living standards between large and small cities. As the market system is far from equilibrium, it is sensible to analyze the rank-size distribution of cities in terms of economic indicators. One objective of this paper is to identify and explain the differences in the emerging urban hierarchy based on population and economic indicators in Guangdong province.

The issue of defining the population size of a Chinese city is considered first. Indeed, it is not an easy task as the population living in the city is not unarguably considered as urban population $[2,44]$. There are three main reasons. First, some Chinese cities especially newly designated countylevel cities usually include large rural areas with large rural population [43]. Such a county-level city has usually been converted from a whole county which is, excluding designated towns under its administration, normally considered as a rural area.

Second, population in China is officially classified into two categories according to its unique hukou (household registration) system, i.e., agricultural population and nonagricultural population. Non-agricultural population enjoys 
many welfare benefits provided by the state and mostly lives in the urban proper of Chinese cities [25, 34, 54]. Before the 1982 census, only the non-agricultural population was considered as urban population and this definition has been used in many studies [2,7]. But such definition has also become unrealistic. Much of the agricultural population has been employed in the expanding township industries within the town or city boundaries or moved into urban areas but majority of such population remains registered as agricultural population.

Third, since 1985 rural migrants have been allowed to move into urban areas and to be registered as temporary population [28]. Such registered or unregistered rural migrants are often called floating population (temporary population or non-hukou population). But the official urban population statistics usually only include the hukou population with permanent local hukou while non-hukou population is excluded. Thus there is no unique definition of urban population in China. In this paper, the non-agricultural population, the hukou population and the total population (including the temporary population) will be used to measure the size of a city. Instead of choosing only one indicator, these three indicators give a complete picture of the population-size of a city and also show how different urban hierarchy will be due to different definitions of urban population.

In addition to population indicators, GDP, commercial wholesale and retail value, and total retail value are also used to measure the economic power of a city. The economic data for the cities in China are collected and compiled by the National Bureau of Statistics through the nationwide statistical offices in various cities [55]. The official data from National Bureau of Statistics have been critically reviewed earlier. Despite some inconsistencies and limitations, the official data were considered to be authoritative and reliable as western-style accounting methods have been adopted since 1993 [56].

The population and GDP data for the year 1998 are from Guangdong Statistical Bureau [57]. The data on wholesale and retail value for the year 1997 are from National Bureau of Statistics [55]. The temporary population data for nine cities including Guangzhou, Shenzhen, Nanhai, Jiangmen, Taishan, Xinhui, Kaiping, Heshan and Enping are extracted from various yearbooks of these cities [58-61]. The temporary population (non-hukou population) in the remaining cities in Guangdong is estimated using the ratio of nonhukou population to total population estimated from the $1 \%$ sampling data in 1995 [62]. The $1 \%$ population sample survey was the best source for the non-hukou population of various cities. The total population of a city is then obtained by adding the temporary population to hukou population.

The rank-size analysis in this paper will cover all the cities in Guangdong. In Guangdong, there were two kinds of cities, i.e., prefecture-level cities and county-level cities. A prefecture-level city may administer an urban proper and some county-level cities or counties. In this paper, a prefecture-level city refers to its urban proper and excludes any county-level units under its administration. Guangdong had 21 prefecture-level cities and 33 county-level cities in 1998. In addition, there were 46 counties in the province. Fig. (1) shows the distribution of cities and counties in Guangdong in 1998.
In terms of methodology, the rank-size distribution is used as a benchmark to measure the distribution of urban population and economic indicator in the urban system in Guangdong. Zipf's rank-size rule $(\mathrm{q}=1)$ or more general rank-size distribution can be described by the following formula:

$$
P_{r}=\frac{P_{1}}{r^{q}}
$$

Here $P_{r}$ is the population size of the city ranked r. $q$ is the coefficient.

To see whether the urban system in Guangdong province conforms to the rank-size rule, expected values of various indicators have been calculated by dividing the value of the top city by the ranks of various cities using the following formula:

$$
E_{i r}=\frac{X_{i 1}}{r}
$$

Here $X_{i 1}$ is the largest value of indicator $i$ of the top city; $E_{i r}$ is the expected value of the indicator $i$ of the city ranked r. The correlation coefficients between the real values and expected values of particular indicators are calculated.

The squared Euclidean distance is also used to measure the difference between the expected values and real values of an indicator for various cities. To make it comparable, all values for an indicator are standardized so that the maximum value is one using the following formula:

$$
\begin{gathered}
X_{i r}^{s}=\frac{X_{i r}}{X_{i 1}} \\
E_{i r}^{s}=\frac{E_{i r}}{E_{i 1}}
\end{gathered}
$$

Here $\mathrm{X}_{\mathrm{ir}}$ and $\mathrm{X}_{\mathrm{ir}}^{\mathrm{s}}$ are the real and the standardized values of indicator $i$ of the city ranked $r$; $E_{\text {ir }}$ and $E_{\text {ir }}^{\mathrm{s}}$ are the expected and the standardized value of the indicator $i$ of the city ranked $r$.

Squared Euclidean distance $\left(D_{i}\right.$ for indicator i) is then calculated in the following:

$$
D_{i}=\sqrt{\sum_{r}\left(X_{i r}^{s}-E_{i r}^{s}\right)^{2}}
$$

In most analyses of rank-size distribution of cities, the focus is on the fitness of the whole urban system against the rank-size distribution. However, it is argued here that it is especially important to examine the fitness of top cities which are the most important in the urban system. An urban system may found to be fit with the rank-size rule very well but the top two cities may be at odds of the rank-size rule. This paper proposes to give special consideration of top two, four and ten cities in the urban system to compliment the overall measure of fitness based on Squared Euclidean distance.

Thus primacy index, four city primacy index, the share of top ten cities and rank-size distribution of above six population and economic indicators will be used to analyze the urban system of 54 cities in Guangdong. The first two indexes measure the relative positions of top two and top four cities. 


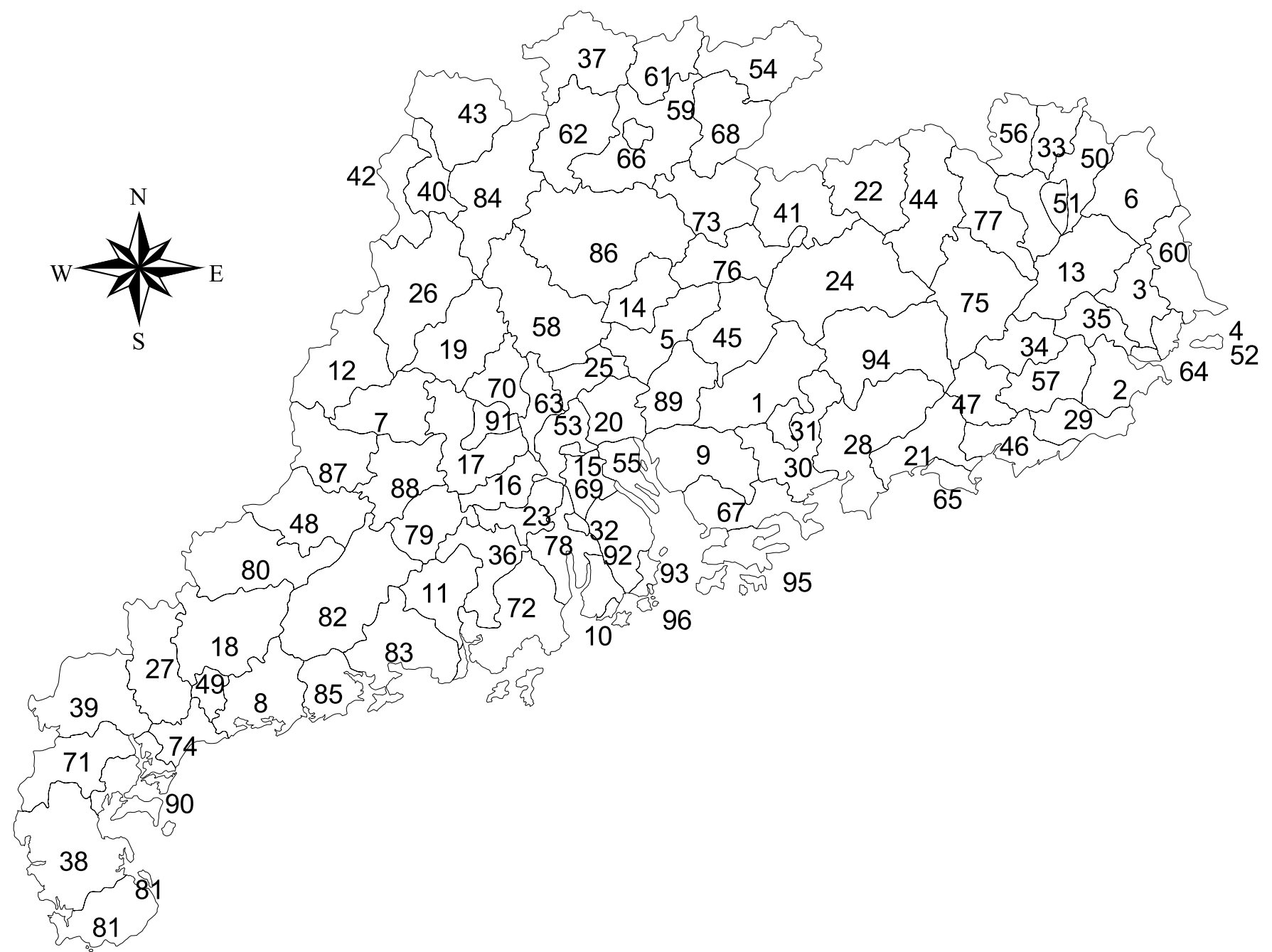

Notes:

$\begin{array}{ll}\text { 1. Boluo } & \text { 21. Haifeng } \\ \text { *2. Chaoyang } & \text { 22. Heping } \\ \text { *3. Chaozhou } & * 23 \text {. Heshan } \\ \text { *4. Chenghai } & * 24 \text {. Heyuan } \\ \text { *5. Conghua } & * 25 . \text { Huadu } \\ \text { 6. Dapu } & \text { 26. Huaiji } \\ \text { 7. Deqing } & * 27 . \text { Huazhou } \\ \text { 8. Dianbai } & \text { 28. Huidong } \\ \text { *9. Dongguan } & \text { 29. Huilai } \\ \text { 10. Doumen } & * 30 . \text { Huiyang } \\ \text { *11. Enping } & * 31 . \text { Huizhou } \\ \text { 12. Fengkai } & * 32 . \text { Jiangmen } \\ \text { 13. Fengshun } & \text { 33. Jiaoling } \\ \text { 14. Fogang } & \text { 34. Jiexi } \\ \text { *15. Foshan } & * 35 . \text { Jieyang } \\ \text { *16. Gaoming } & * 36 . \text { Kaiping } \\ \text { *17. Gaoyao } & * 37 . \text { Lechang } \\ \text { *18. Gaozhou } & * 38 . \text { Leizhou } \\ \text { 19. Guangning } & * 39 . \text { Lianjiang } \\ \text { *20. Guangzhou } & \text { 40. Liannan }\end{array}$
41. Lianping
42. Lianshan
*43. Lianzhou
44. Longchuan
45. Longmen
*46. Lufeng
47. Luhe
*48. Luoding
*49. Maoming
50. Meixian
*51. Meizhou
52. Nan`ao
*53. Nanhai
*54. Nanxiong
*55. Panyu
56. Pingyuan
*57. Puning
*58. Qingyuan
59. Qujiang
60. Raoping

81. Xuwen

*82. Yangchun

*83. Yangjiang

84. Yangshan

85. Yangxi

*86. Yingde

87. Yu`nan

*88. Yunfu

*89. Zengcheng

*90. Zhanjiang

*91. Zhaoqing

*92. Zhongshan

*93. Zhuhai

94. Zijin

*95. Hong Kong

*96. Macau

(* refer to cities and others are counties. Hong Kong and Macau are not part of Guangdong province)

Fig. (1). The administrative division of Guangdong province in 1998. 
In the case of non-agricultural population, for example, primacy index is the ratio of the non-agricultural population of the largest city to that of the second largest city. Four city primacy index is the ratio of the non-agricultural population of the largest city to the total non-agricultural population of the second, third and fourth largest cities. The third index measures the relative position of top ten cities in the urban system, i.e., the non-agricultural population share of top ten cities in total population of all cities. These indexes can be defined similarly for other population and economic indicators.

Table 1 shows the primacy index, four city primacy index and the share of top ten cities in an ideal urban system of 54 cities conforming to Zipf's rank-size rule [46]. In such an ideal urban system, the primacy index is 2 and the four city primacy index is 0.92 with $64.02 \%$ of the population of the urban system concentrated in top ten cities.

\section{DIFFERENTIALS IN THE RANK-SIZE DISTRIBU- TION OF THE URBAN SYSTEM USING POPULA- TION AND ECONOMIC INDICATORS}

This section will examine the differentials in the ranksize distribution of the urban system using population and economic indicators in Guangdong province. The primacy index, four city primacy index, the share of top ten cities and the fitness measures for the urban system by various indicators are presented in Table 1. Table 2 presents the top ten cities in the urban system in Guangdong according to various indicators.

\section{Urban Hierarchy Based on Population Size of Cities}

As mentioned before, three different definitions of urban population will be used to represent different urban hierarchies in Guangdong. The first definition of urban population refers to the non-agricultural population. Under such defini-

Table 1. Primacy Index, Four City Primacy Index and Other Indicators of the Urban System in Guangdong 1998

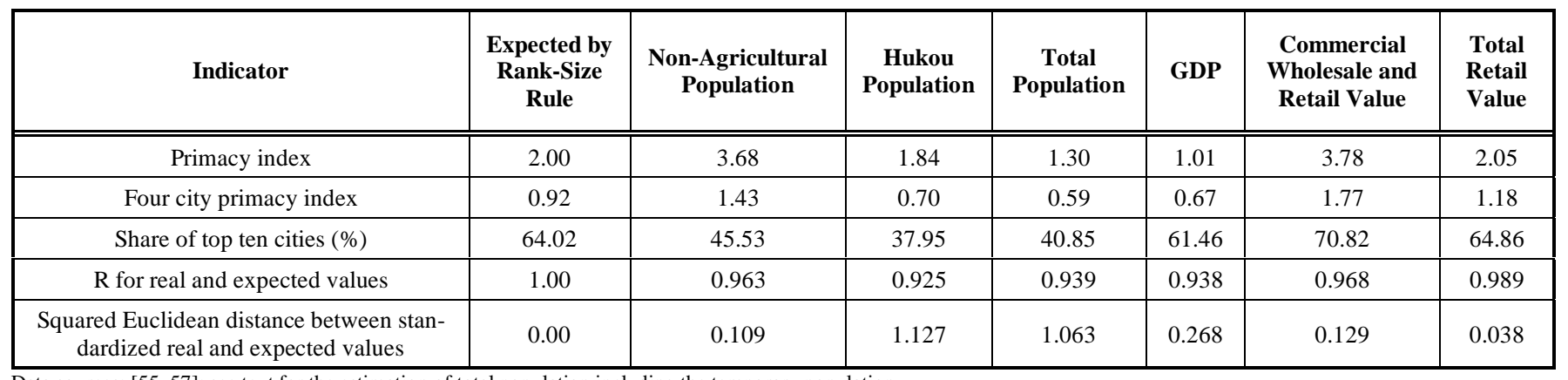

Data sources: [55, 57]; see text for the estimation of total population including the temporary population.

Table 2. Top Ten Cities in the Urban System in Guangdong 1998 (US\$1= RMB 8.28 in 1998)

\begin{tabular}{|c|c|c|c|c|c|c|}
\hline 2 & $\begin{array}{c}\text { Shenzhen } \\
899 \\
\end{array}$ & $\begin{array}{c}\text { Chaoyang } \\
2175 \\
\end{array}$ & $\begin{array}{c}\text { Shenzhen } \\
3606 \\
\end{array}$ & $\begin{array}{c}\text { Shenzhen } \\
128.902 \\
\end{array}$ & $\begin{array}{c}\text { Shenzhen } \\
5070 \\
\end{array}$ & $\begin{array}{c}\text { Shenzhen } \\
3265 \\
\end{array}$ \\
\hline 4 & $\begin{array}{c}\text { Zhanjiang } \\
589 \\
\end{array}$ & $\begin{array}{c}\text { Dongguan } \\
1487 \\
\end{array}$ & $\begin{array}{c}\text { Dongguan } \\
2140 \\
\end{array}$ & $\begin{array}{l}\text { Nanhai } \\
28.254 \\
\end{array}$ & $\begin{array}{c}\text { Foshan } \\
1994 \\
\end{array}$ & $\begin{array}{c}\text { Dongguan } \\
1102 \\
\end{array}$ \\
\hline 5 & $\begin{array}{c}\text { Shaoguan } \\
431 \\
\end{array}$ & $\begin{array}{c}\text { Gaozhou } \\
1437 \\
\end{array}$ & $\begin{array}{c}\text { Puning } \\
2078 \\
\end{array}$ & $\begin{array}{c}\text { Shunde } \\
26 \\
\end{array}$ & $\begin{array}{c}\text { Dongguan } \\
1922 \\
\end{array}$ & $\begin{array}{c}\text { Nanhai } \\
905 \\
\end{array}$ \\
\hline 8 & $\begin{array}{c}\text { Chaoyang } \\
390 \\
\end{array}$ & $\begin{array}{c}\text { Zhanjiang } \\
1308 \\
\end{array}$ & $\begin{array}{c}\text { Lianjiang } \\
1459 \\
\end{array}$ & $\begin{array}{c}\text { Zhuhai } \\
22 \\
\end{array}$ & $\begin{array}{c}\text { Shunde } \\
1731 \\
\end{array}$ & $\begin{array}{c}\text { Zhanjiang } \\
747\end{array}$ \\
\hline 9 & $\begin{array}{c}\text { Nanhai } \\
381 \\
\end{array}$ & $\begin{array}{c}\text { Zhongshan } \\
1301 \\
\end{array}$ & $\begin{array}{c}\text { Zhanjiang } \\
1456 \\
\end{array}$ & $\begin{array}{c}\text { Shantou } \\
21 \\
\end{array}$ & $\begin{array}{c}\text { Nanhai } \\
1686 \\
\end{array}$ & $\begin{array}{c}\text { Shunde } \\
619 \\
\end{array}$ \\
\hline 10 & $\begin{array}{c}\text { Dongguan } \\
378 \\
\end{array}$ & $\begin{array}{c}\text { Leizhou } \\
1272\end{array}$ & $\begin{array}{c}\text { Zhongshan } \\
1367 \\
\end{array}$ & $\begin{array}{c}\text { Zhanjiang } \\
16\end{array}$ & $\begin{array}{c}\text { Xinhui } \\
1270 \\
\end{array}$ & $\begin{array}{c}\text { Foshan } \\
597 \\
\end{array}$ \\
\hline
\end{tabular}

Data source: $[55,57]$; see text for the estimation of total population including the temporary population. 
tion, Guangzhou, Shenzhen, Shantou and Zhanjiang were the top four cities in 1998 with non-agricultural population of 3.3 million, 0.9 million, 0.8 million and 0.6 million respectively. Similar to the situation of pre-reform period, Guangzhou was still a primate city in Guangdong with primacy index of 3.68. The four city primacy index was also as high as 1.43. Both indexes were larger than those in an urban system conforming to the rank-size rule. The main reason is the continuous control of migrants in acquiring local household registration. Thus the growth of non-agricultural population in other cities such as Shenzhen has not challenged the primate city status of Guangzhou.

Figs. (2) and (3) present the real and expected rank-size distributions of 54 cities based on the non-agricultural population. It is clear that the change in the size of top two cities is steeper than that of rank-size rule but the change in size from the fourth city to the $54^{\text {th }}$ city is less steep. Top ten cities accounted for $45.53 \%$ of the non-agricultural population in the urban system, much less than the expected $64.02 \%$ in an urban system conforming to the rank-size rule. Nevertheless, overall, the correlation coefficient (0.963) and the Squared Euclidean distance (0.109) indicate that the real and expected rank-size distributions of non-agricultural population are close. It is clear that whether the top two, four, ten or all cities are taken into account is vital in determining whether the city-size distribution is consistent with rank-size rule. One overall index such as correlation coefficient may hide great unfitness among top cities in an urban system.

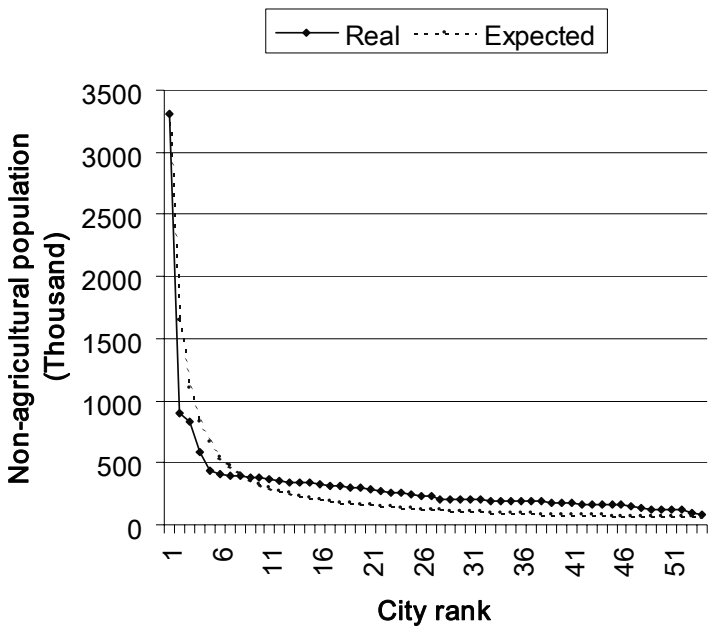

Fig. (2). Rank-size distribution of non-agricultural population in cities in Guangdong 1998.

The second definition of urban population is the hukou population which includes both the agricultural population and non-agricultural population with household registration in the city. Some cities had a large share of agricultural population resulting in a different rank-size distribution of cities in the urban system. Guangzhou, Chaoyang, Puning and Dongguan were the top four cities in 1998 with hukou

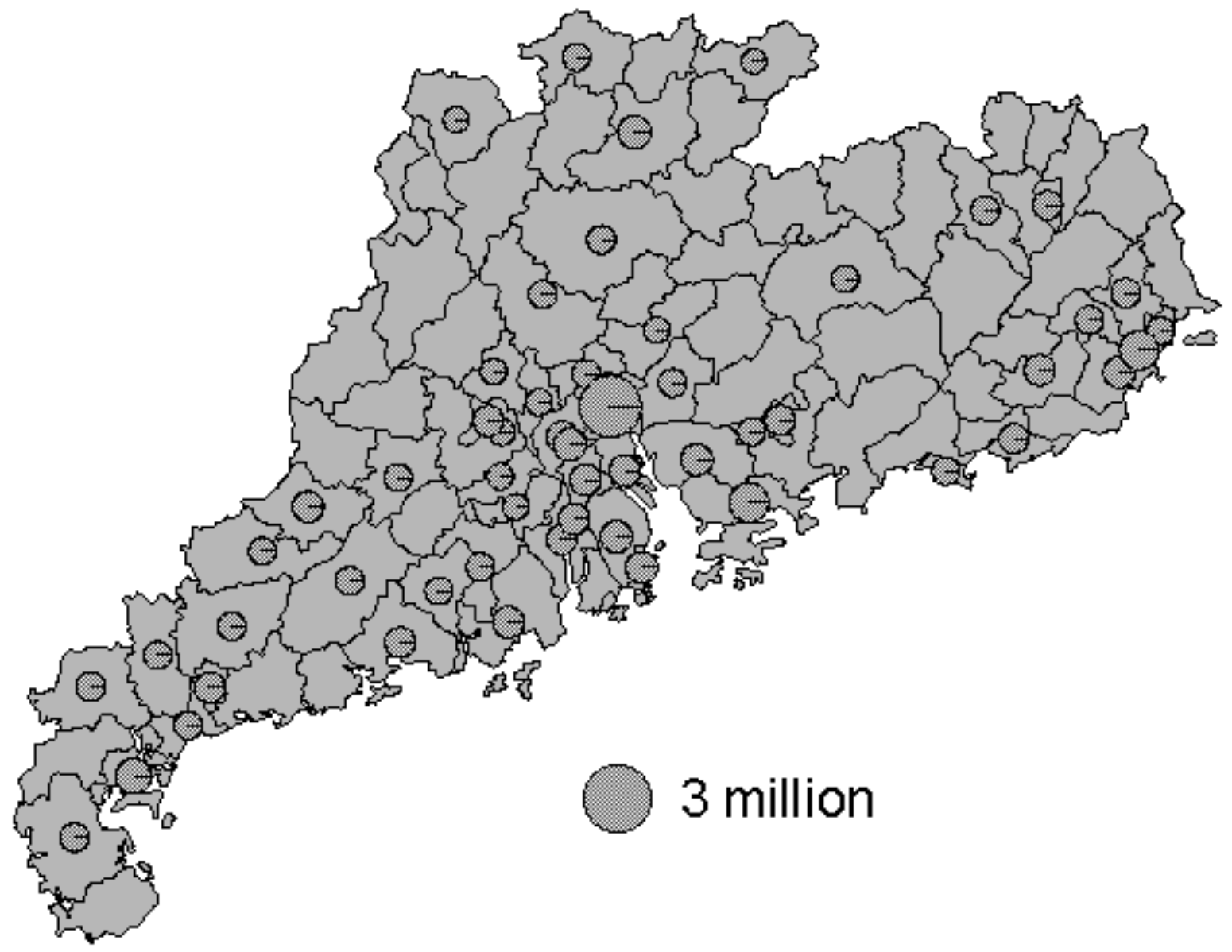

Fig. (3). Non-agricultural population in cities in Guangdong 1998. 
population of 4.0 million, 2.2 million, 1.80 million and 1.5 million respectively. As the provincial capital, Guangzhou had a large hukou population and kept its top position for a long time. Due to hukou control, hukou population only grew slowly in many Chinese cities. The relaxed mobility of temporary non-hukou population did not increase the size of hukou population in many cities. Shenzhen which often considered the second largest city in the province only had a small agricultural population with local hukou as most of such population had been granted non-agricultural population status in the process of rapid urbanization. Thus it only had 1.15 million hukou population and ranked $12^{\text {th }}$ in Guangdong as its large non-hukou population was not counted.

In the urban hierarchy based on the hukou population in various cities, the primacy of Guangzhou was weaker than in the case of non-agricultural population. Its primacy index was only 1.84 . The four city primacy index was also as small as 0.70 . Both indexes are smaller than those in an urban system conforming to the rank-size rule. The key reason is that Guangzhou only had a small proportion of agricultural population as the most developed city in the province while other cities especially those converted from previous counties had a substantial proportion of agricultural population. When the agricultural population and non-agricultural population were combined together, the primacy of Guangzhou was smaller than in the case of non-agricultural population.

Fig. (4) presents the real and expected rank-size distribution of 54 cities based on the hukou population. It is clear that the second and third largest cities were stronger than in the case of non-agricultural population and the change in the size from the fourth city to the $54^{\text {th }}$ city was less steep. Top ten cities accounted for only $37.95 \%$ of the hukou population in the urban system indicating more even distribution of hukou population in the system. The correlation coefficient (0.925) and the Squared Euclidean distance (1.127) indicate that the expected and real rank-size distributions of hukou population are less close than those of non-agricultural population (Figs. 2 and 4).

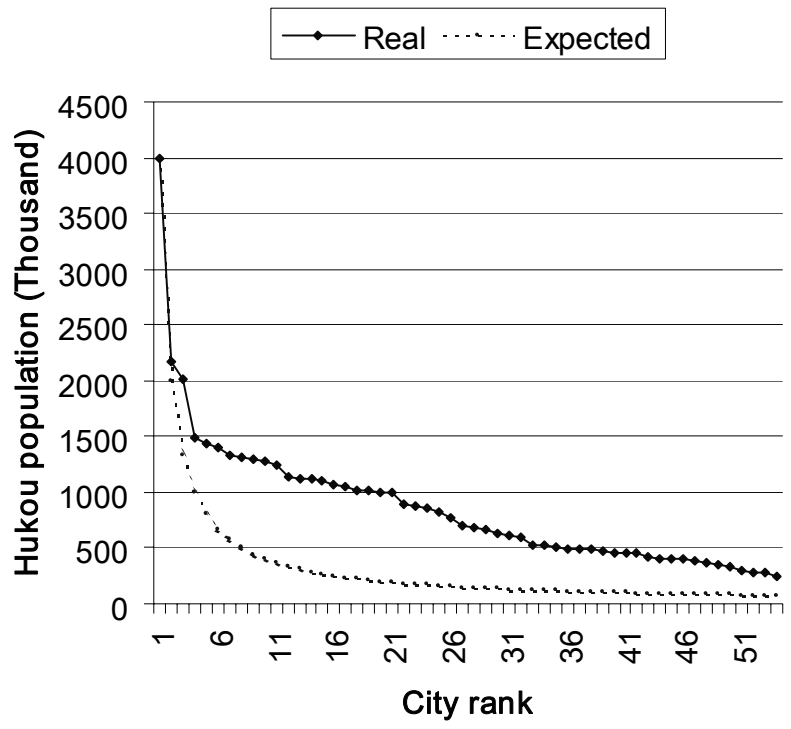

Fig. (4). Rank-size distribution of hukou population in cities in Guangdong 1998.
The third definition of urban population is the total population including both the hukou population and temporary population. In the reform period after the early 1980s, Guangdong and especially the cities in PRD has become the main destination for rural migrants from both Guangdong and other provinces. According to the estimation in this paper, there was a temporary population of 7.26 million in the 54 cities in Guangdong. Fig. (5) present the real and expected rank-size distribution of 54 cities based on the total population.

In terms of total population, Guangzhou, Shenzhen, Chaoyang and Dongguan were the top four cities in 1998 with total population of 4.7 million, 3.6 million, 2.2 million and 2.1 million respectively. When temporary population was included, Shenzhen became the second largest city in Guangdong again due to its large temporary population. The size of total population in Shenzhen was very close to that of Guangzhou. As a result, Guangzhou's primacy was significantly weakened with primacy index of only 1.30. The four city primacy index was also as small as 0.59 . Top ten cities accounted for $40.85 \%$ of the total population in the urban system. These indicators show that the rank-size distribution of the total population was less steep than expected from the rank-size rule.

But except top cities such as Guangzhou and Shenzhen, the impact of temporary population was small on the distribution of the total population of other cities. Thus the correlation coefficient (0.939) and the squared Euclidean distance (1.063) indicate that the difference between the expected and real rank-size distributions of total population is similar to that of hukou population (Figs. 4 and 5). The distribution of the total population is also more even than that of an urban system conforming to the rank-size rule. However, the second largest city in terms of total population (Shenzhen) was not the same second largest city in terms of hukou population (Chaoyang). The real urban hierarchy was changed when different population indicators were used while the rank-size distribution appeared to be similar.

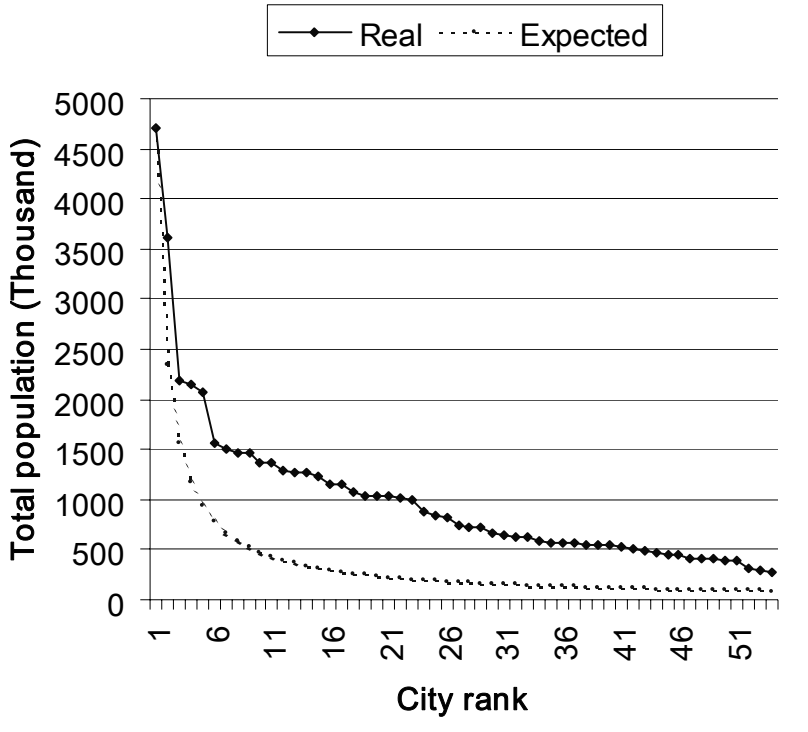

Fig. (5). Rank-size distribution of total population in cities in Guangdong 1998. 
The above analyses show the complicated nature of urban hierarchy in the urban system in Guangdong due to a peculiar population registration system. The issue of which of the above three definitions is the best definition of urban population has not been solved as each of them has its limitations and advantages. The non-agricultural population is a strict definition of urban population which was used commonly before 1982 census. But this definition excludes much agricultural population in cities who actually no longer engages in agriculture but is unable to acquire non-agricultural population status. The hukou population overcomes the above problem but it may also include too much agricultural population who still engages in agriculture. The definition of non-agricultural population and that of hukou population exclude temporary population which has become an important part of population in many cities. The total population solves the above problem by including temporary population as well. But the definition of total population has the same problem as the definition of hukou population and may include too much agricultural population who still engages in agriculture.

\section{Urban Hierarchy Based on Economic Indicator of Cities}

As mentioned before, traditionally, rank-size analysis of urban system has been focused on population indicators. Due to significant inequality in GDP per capita and the level of development among various cities, population size of a city is not a good surrogate for the economic power of a city. Thus it is sensible to examine the rank-size distribution of economic indicators to reveal the economic inequality among various cities in an urban system. This also provides an opportunity to compare the rank-size distribution of economic indicators versus that of population size in an urban system especially under a condition of socialist market economy. Three economic indicators are considered in this section.

In terms of GDP, Guangzhou, Shenzhen, Dongguan and Nanhai were the top four cities in 1998. Clearly, Guangzhou and Shenzhen had the same economic power and they were two dominant economic centers in the urban system in Guangdong. This situation was different from that of the early 1980s when Guangzhou was the dominant economic center in PRD and Guangdong [38, 40]. Shenzhen economy grew rapidly in the 1980s and 1990s due to dramatic inflow of foreign capital and temporary population. The primacy index was 1.01 in terms of GDP. The four city primacy index was also as small as 0.67 . These two indexes indicate that the distribution of GDP was far away from the rank-size rule. But the top ten cities accounted for $61.46 \%$ of GDP in the urban system and this share was close to an urban system conforming to the rank-size rule. Fig. (6) presents the real and expected rank-size distribution of 54 cities based on the GDP. Other than the top two cities, the real and expected distributions of GDP among various cities were close, confirmed by small squared Euclidean distance (0.268). The correlation coefficient of 0.938 was not so reliable as it was close to the case of total population which had much larger difference in the expected and real distributions. This case explains why squared Euclidean distance is preferred to measure the difference between real and expected distributions of various indicators.

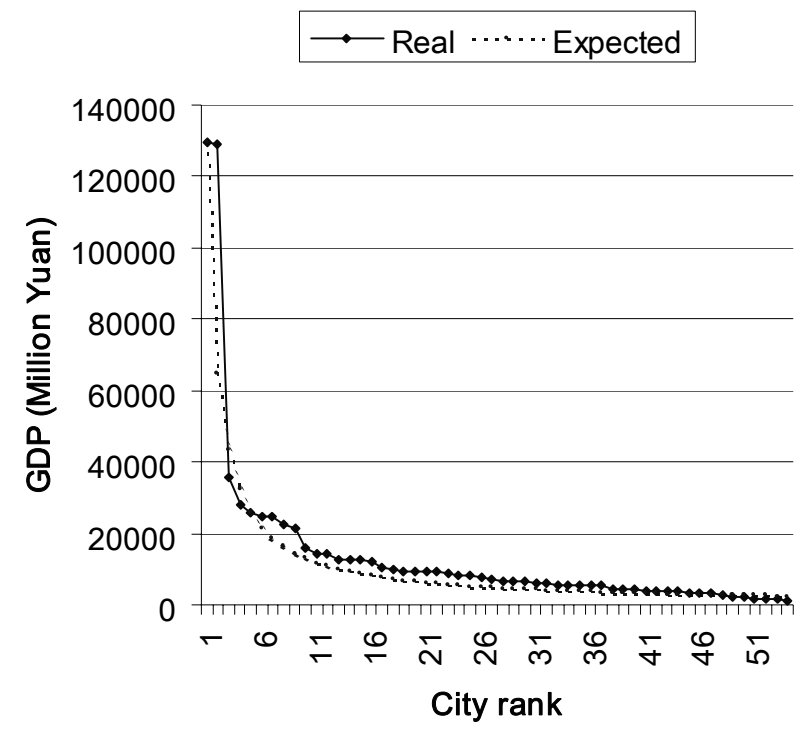

Fig. (6). Rank-size distribution of GDP in cities in Guangdong 1998.

Similar to the non-agricultural population, Guangzhou has a strong primacy in terms of the commercial wholesale and retail value, with primacy index of 3.78. In terms of the total retail value, the primacy index was 2.05 which was close to the rank-size rule. Guangzhou is clearly the trading center of the province. Despite of the large GDP in Shenzhen, its trading volume was still much smaller than Guangzhou. It is also interesting to note that, similar to the distribution of GDP among various cities in Guangdong, over $65 \%$ of the trading value was concentrated in top ten cities. Guangzhou, Shenzhen and Shantou were the top three cities with the largest commercial wholesale and retail value, and the total retail value. The rank-size distribution of the commercial wholesale and retail value among the top ten cities was much steeper than that of rank-size rule indicating strong primacy. But the change in the commercial wholesale and retail value from the $10^{\text {th }}$ city to the $54^{\text {th }}$ city and the change in the total retail value from the $3^{\text {th }}$ city to the $54^{\text {th }}$ city were close to the rank size rule (Figs. 7 and 8). Overall, the distributions of these two indicators were close to the rank-size rule indicated by large correlation coefficients (0.969 and 0.989) and small squared Euclidean distances (0.129 and 0.038).

\section{A Discussion on Measuring Urban Hierarchy Using Dif- ferent Measures}

Primacy index, four city primacy index, share of top ten cities, correlation coefficient and squared Euclidean distance have been used to assess whether the rank-size distribution of an indicator conforms to Zipf's rank-size rule. It is clear that different indexes assess part or all of the cities in the urban system. Primacy index, four city primacy index and the share of top ten cities focus on the top 2, 4, and 10 cities while correlation coefficient and squared Euclidean distance measures the whole urban system. The case of the urban system in Guangdong indicates that these different measures are not consistent and different conclusions may be obtained.

In terms of top two cities, Guangzhou's primacy was clear in the non-agricultural population and the commercial 
wholesale and retail value. Guangzhou's primacy was less clear in the total hukou population, the total retail value, the total population and GDP.

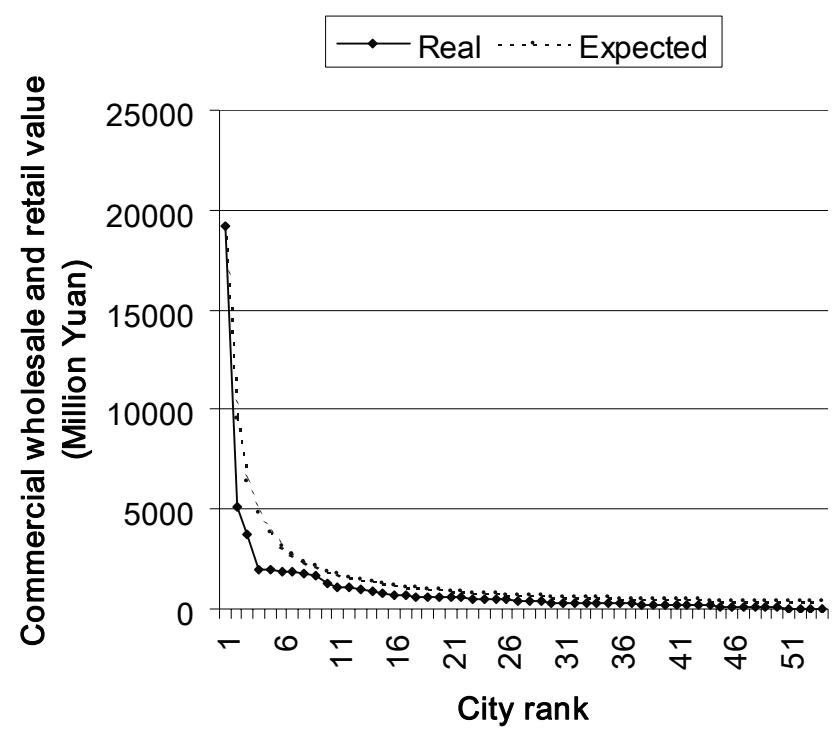

Fig. (7). Rank-size distribution of commercial wholesale and retail value in cities in Guangdong 1997.

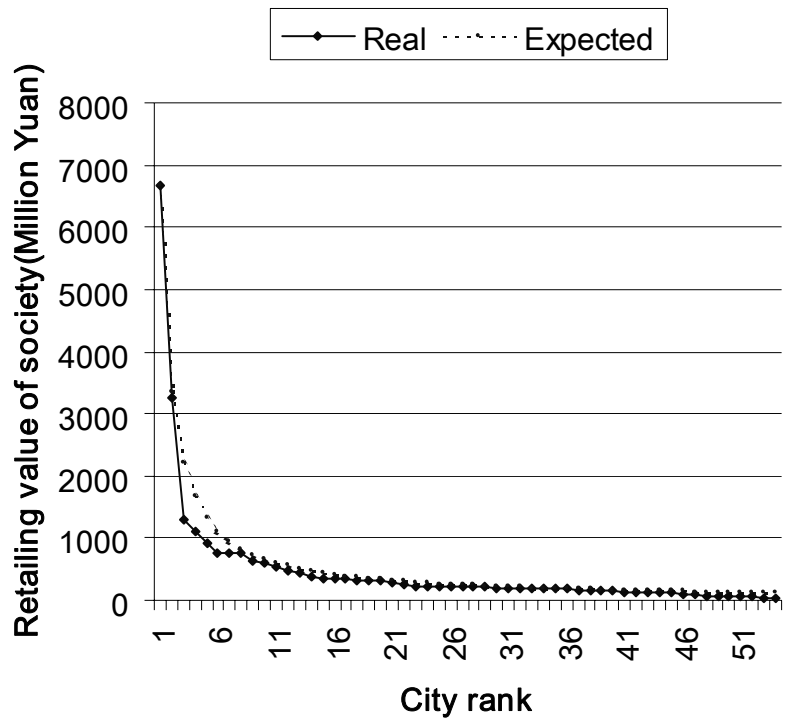

Fig. (8). Rank-size distribution of retailing value in cities in Guangdong 1997.

Taking all cities in the urban system of Guangdong into account, the correlation coefficients between expected and real values of six indicators were all highly significant at the 0.001 level. This is similar to most analyses of the rank-size distribution. The high correlation is related to the nature of the data as the rank variable is a transformation of the size variable [52]. Thus the correlation coefficient is not a satisfactory measure. Particularly, the difference between the expected value and the real value is much larger in the case of total population than the case of GDP, but the correlation coefficients are very close for the two indicators, 0.939 and 0.938 respectively. The squared Euclidean distance is more satisfactory. It indicated that the distribution of total retail value was the most close to the rank-size rule while the dis- tributions of the hukou population and total population were the least close to the rank-size rule. Indeed, the distributions of hukou population and total population were more even than the rank-size rule.

The findings in this section indicate that the rank-size distributions of an urban system are not the same when different population and economic indicators are used to represent city size. Such dissimilar distributions reflect inequality, differences in industrial structures, non-hukou population and migration from rural areas in industrial transformation. Consideration of economic concentration may be as important as that of population concentration as the issues of inequality and unbalanced development are best assessed in terms of per capita basis.

\section{THE ROLE OF ECONOMIC DEVELOPMENT IN THE PROCESS OF URBANIZATION}

Scale and agglomeration economies, and the level of economic development are powerful explanations for urban growth and urban systems in developed countries. The role of economic development in the urbanization of less developed countries is not so certain due to the notions of overurbanization and under-urbanization [31]. In the case of China, Fan argued that institutional factors including policy, socialist administrative system and local governments are more important than economic factors in explaining the growth of various cities in the urban system [7].

It is argued here that there are economic foundations for any policy change and institutional intervention. For example, for a county to acquire the status of a designated city in China, it has to reach certain thresholds of non-agricultural population and economic power. Some counties may be designated as a city due to special considerations and back-door lobby. But such cases may be considered as exceptions rather than the norm. Well-qualified counties are unlikely to be denied the chance of acquiring the city status. Thus economic development is likely to be a key factor of urban growth despite of the significant influence of institutional factors. The question is whether a study is focused on the institutional factors or the economic factors and at what spatial scale. In Guangdong, there is little difference in the urbanization policy except Guangzhou and the role of economic development is likely to be more important in the growth of individual cities.

It cannot be assumed that economic growth will inevitably result in urban growth as both under-urbanization and over-urbanization could happen in developing countries [31]. In Western countries, economic growth will not result in further urban expansion due to high level of urbanization. As mentioned before, policy on migration especially the temporary population has been relaxed and urban development has been encouraged by the government in the post-reform China. Thus a close relationship between economic development and urbanization is expected. This section attempts to explore the relationship between the economic development and urbanization using two sets of data. First, the levels of economic development and urbanization between PRD and non-PRD areas in Guangdong are compared. Second, time series data on economic growth, urban built-up area and employment of nine prefecture-level cities in PRD were used 
to illustrate the role of economic development in the process of urbanization.

The following will first contrast the differential urbanization in PRD and non-PRD areas in the province. Table 3 presents the population, GDP, share of non-agricultural population and GDP per capita in Guangdong province. It is clear that the PRD region had a more advanced economy than non-PRD region. The PRD region accounted for $67 \%$ of the GDP with only $31.2 \%$ of the total population in the province. The population share of PRD region would still be lower than its GDP share even if a temporary population of 7 million was included in the total population of PRD [40]. Economic concentration in the PRD region was a result of the regional polarization process reinforced by the good economic foundation of the region, geographical proximity to Hong Kong, capital investment from Hong Kong and abroad, local government initiatives, and favorable "one-step ahead" reform and open-door policies in the region [38, 40].

On the other hand, cities were relatively concentrated in the PRD region due its significant economic development in the province [40]. Among 28 area units in PRD, there were 25 cities and only three counties. Among 72 area units in Non-PRD region, there were 29 cities and as many as 43 counties. Using most strict non-agricultural population as the definition of the urban population, PRD was the most urbanized region in Guangdong. For the PRD region as a whole, non-agricultural population accounted for $47.3 \%$ of the total population in 1998. But in the non-PRD region, the share of non-agricultural population in the total population was as low as $23.6 \%$.

The relationship between economic development and urban growth is better assessed through time-series data. Consistent data were collected for nine prefecture-level cities over the period 1990-1998 in the PRD region [63].

Fig. (9) presents the GDP growth in various cities in the period 1990-1998. The GDP data are based on the current price and are not directly comparable between years. However, the data do illustrate the relative growth of various cities. Guangzhou's GDP share in the PRD region declined from $42.80 \%$ in 1980 to $24.44 \%$ by 1990 . The relative decline in the 1990s was much less and its GDP share was $22.20 \%$ in 1998 . On the contrary, the rise of Shenzhen was exceptional. Its GDP share increased from $1.82 \%$ in 1980 to $13.56 \%$ in 1990 and $22.04 \%$ in 1998 . Shenzhen caught up Guangzhou rapidly in the 1990s. Rapid economic growth in Shenzhen was powered by vigorous industrialization and upgrading of its economic structure. By 1998, Shenzhen had become a prominent center of high-tech industry in China. High-tech industry output reached RMB 81 billion accounting for $35.4 \%$ of the total industrial output of the city [64].

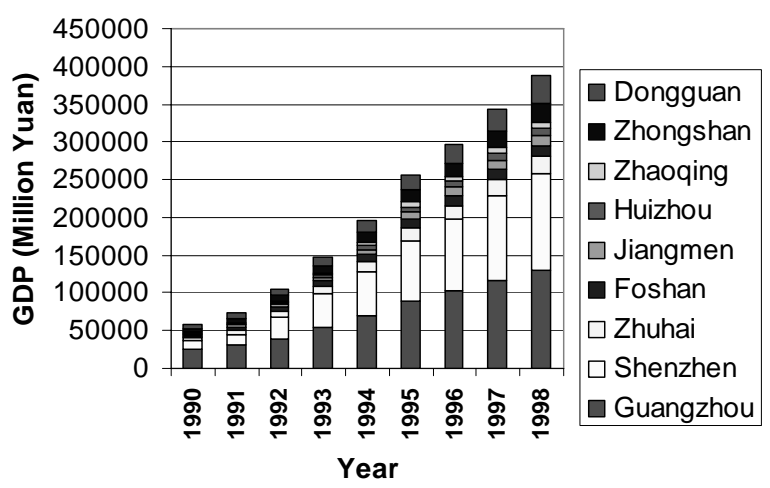

Fig. (9). Growth of GDP in the prefecture-level cities in Pearl River Delta 1990-1998.

Rapid economic growth is instrumental to urban growth. The size of built-up area is a good indicator of urban growth which can be measured physically. Fig. (10) presents the expansion of built-up area of the prefecture-level cites in PRD over the period 1990-1998. It is clear that most cities experienced sizable growth in this period. Guangzhou had the largest built-up area which grew from $182 \mathrm{~km}^{2}$ to 275

Table 3. Population and GDP Indicators by Area Types in Guangdong 1998

\begin{tabular}{|c|c|c|c|c|c|c|}
\hline Areas & No. of Units & $\begin{array}{l}\text { Non-Agricultural } \\
\text { Population } \\
\text { (Thousand) }\end{array}$ & $\begin{array}{l}\text { Agricultural } \\
\text { Population } \\
\text { (Thousand) }\end{array}$ & $\begin{array}{c}\text { Total } \\
\text { Population } \\
\text { (Thousand) }\end{array}$ & $\begin{array}{c}\text { GDP } \\
\text { (RMB Billion) }\end{array}$ & $\begin{array}{c}\text { Share of } \\
\text { Non-Agricultural } \\
\text { Population }(\%)\end{array}$ \\
\hline Prefecture-level city & 9 & 6687 & 3356 & 10043 & 387 & 66.6 \\
\hline County-level city & 16 & 3409 & 7205 & 10614 & 179 & 32.1 \\
\hline Non-Pearl River Delta & 72 & 11617 & 37525 & 49142 & 288 & 23.6 \\
\hline Prefecture-level city & 12 & 3839 & 2976 & 6815 & 81 & 56.3 \\
\hline County-level city & 17 & 3650 & 15590 & 19240 & 97 & 19.0 \\
\hline County & 43 & 4128 & 18959 & 23087 & 110 & 17.9 \\
\hline County & 46 & 4605 & 20201 & 24806 & 128 & 18.6 \\
\hline
\end{tabular}


$\mathrm{km}^{2}$ in the period. Shenzhen was the second largest city in terms of built-up area which grew from $69 \mathrm{~km}^{2}$ to $129 \mathrm{~km}^{2}$ in the same period.

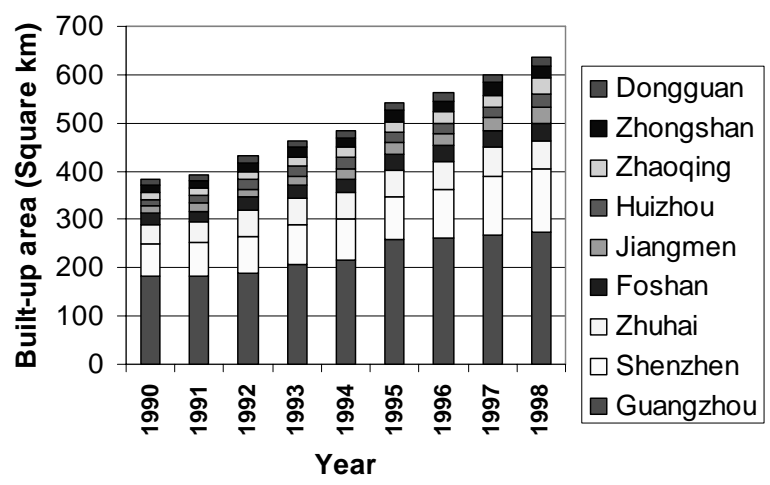

Fig. (10). Growth of built-up area in the prefecture-level cities in Pearl River Delta 1990-1998.

Other than the built-up area, population is the most preferable indicator of the size of a city. However, as mentioned before, the official population statistics for Chinese cities usually did not include the temporary non-hukou population. The data on temporary population were collected in some surveys like the 1990 census and the $1 \%$ population sampling survey in 1995. But no consistent data for all prefecture-level cities for the whole period of 1990-1998 were available. Thus this section will use the number of employees as an approximate indicator of population size in various cities. The employment data cover most non-hukou population as well as hukou population who were employed. Of course, this indicator will exclude dependent population as well as some unemployed people.

Fig. (11) presents the growth in employment in various cities in the period 1990-1997. Reliable employment data for 1998 were not available. The size of employment in Guangzhou increased from 2.10 million to 2.50 million while the number of employees in Shenzhen increased dramatically from 0.60 million to 2.72 million in the period 1990-1997. The size of employment in Shenzhen had surpassed Guangzhou indeed. As Shenzhen had a higher proportion of migrant workers who usually did not bring their dependents, the total population in Shenzhen was still smaller than Guangzhou. In addition, most migrant workers also lived in quarters provided by employers. Thus Shenzhen's built-up area was not as large as Guangzhou.

Finally, a correlation analysis was conducted and correlation matrixes among three main indicators were calculated for each of the nine prefecture-level cities in the PRD region. The correlation coefficients for Guangzhou and Shenzhen were presented in Tables $\mathbf{4}$ and $\mathbf{5}$ respectively. All correlation coefficients were significant at the 0.05 level. GDP growth had significant correlation with built-up area or the size of employment in all cities confirming the close relationship between economic development and urban growth.

\section{CONCLUSION}

This paper analyzed the urban system in the Guangdong province as a result of uneven development and urbanization under the socialist market economy. Much advance has been made in the study of the new urbanization process in the post reform China. This paper hopes to fill the knowledge gap between the new urbanization process and the emerging new urban system. Recognizing the substantial discrepancy among the rank-size distribution of cities in terms of population and economic indicators especially due to the existence of "temporary population" and the policy of "designating a whole county as a city", the urban system in Guangdong province was analyzed using demographic and economic indicators.

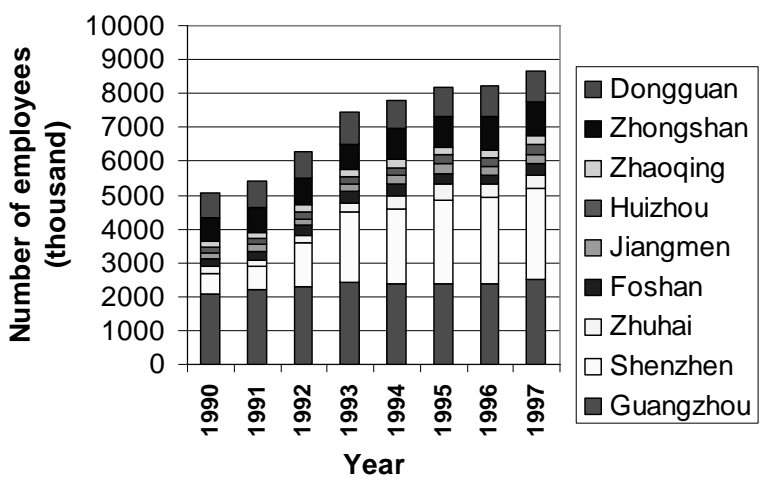

Fig. (11). Growth of employment in the prefecture-level cities in Pearl River Delta 1990-1997.

Table 4. Correlation Coefficients Among Five Indicators in Guangzhou

\begin{tabular}{|l|c|c|c|}
\hline \multicolumn{1}{|c|}{ Indicator } & $\begin{array}{c}\text { Built-Up } \\
\text { Area }\end{array}$ & $\begin{array}{c}\text { Number of } \\
\text { Employees }\end{array}$ & GDP \\
\hline \hline Built-up area & 1 & & \\
\hline Number of years & 9 & & \\
\hline Number of employees & 0.801 & 1 & \\
\hline Number of years & 8 & 8 & \\
\hline GDP & 0.981 & 0.854 & 1 \\
\hline Number of years & 9 & 8 & 9 \\
\hline
\end{tabular}

Note: all correlation coefficients were significant at 0.05 level.

Table 5. Correlation Coefficients Among Three Indicators in Shenzhen

\begin{tabular}{|l|c|c|c|}
\hline \multicolumn{1}{|c|}{ Indicator } & $\begin{array}{c}\text { Built-Up } \\
\text { Area }\end{array}$ & $\begin{array}{c}\text { Number of } \\
\text { Employees }\end{array}$ & GDP \\
\hline \hline Built-up area & 1 & & \\
\hline Number of years & 9 & & \\
\hline Number of employees & 0.802 & 1 & \\
\hline Number of years & 8 & 8 & \\
\hline GDP & 0.958 & 0.929 & 1 \\
\hline Number of years & 9 & 8 & 9 \\
\hline
\end{tabular}


Many previous theoretical and empirical studies of ranksize distribution of cities in an urban system used population size of a city as the key variable and all cities were covered in assessing whether the urban system conforms to rank-size rule. This paper used two innovative approaches in the analysis of the urban system. Firstly, particular focus was given to top two, four and ten cities in the urban system as these leading cities play important roles. Secondly, economic indicators were used directly as alternative indicators of citysize in the analysis of rank-size distribution of cities. A real urban system is unlikely in a state of equilibrium which is assumed in theoretical studies using general-equilibrium economic approach.

The paper found that the primacy of Guangzhou in Guangdong varied by population and economic indicators. The primacy index was the largest in terms of nonagricultural population and commercial wholesale and retail value as Guangzhou continued to be the trading center of the province and the growth of non-agricultural population was largely controlled. The primacy index was close to two (which was the case of Zipf's rank size rule) in terms of hukou population and total retail value. The primacy index was the smallest, just over one, in terms of total population and GDP. Considering city size in terms of total population and GDP, the urban system in the region now has twincenters of Guangzhou and Shenzhen. This is largely due to a large temporary population and dramatic economic growth in Shenzhen.

When the relative positions of top four cities were considered, the four city primacy of the total retail value was close to that of the Zipf's rank-size rule while those of the non-agricultural population and commercial wholesale and retail value were much greater indicating significant primacy of the top city, Guangzhou. The four-city primacy of hukou population, total population and GDP was smaller than that of the Zipf's rank-size rule (0.92). It is clear that the extent of primacy is different between the cases of top two and top four cities. When the relative position of top ten cities in the urban system was considered, non-agricultural population and hukou population showed much even distribution while the distributions of other indicators were much close to that of the Zipf's rank-size rule (top ten city share $64.02 \%$ ). It is clear that this result is different from the case of top two cities. For example, Guangzhou has a significant primacy when top two cities were considered in terms of non-agricultural population but the concentration of non-agricultural population in top ten cities was more even than that of Zipf's ranksize rule.

When all cities in the urban system were considered, correlation coefficient and squared Euclidean distance showed different results. Squared Euclidean distance showed that the difference between the real and expected rank-size distributions was the largest for hukou population and total population and smallest for total retail value.

Overall, the analysis in this paper showed that rank-size distributions of various population and economic indicators were not the same. Urban hierarchy was found to be dependent on which indicator was used to represent city-size. The relative positions of top two, four, ten and all cities in the urban system may not be consistent in terms of their fitness with rank-size rule. These findings pointed out the useful- ness to examine the rank-size distribution of urban size based on various population and economic aspects and the relative positions of top cities in the urban hierarchy.

The current urban system in Guangdong is a result of economic development, urban policy and other institutional factors. Earlier studies have emphasized the role of government policy in the urban development in China $[7,10]$. The paper argued that the role of economic development in also important while acknowledging the effects of institutional factors [25]. Indeed, the different urban hierarchies based on different definitions of urban population are largely a result of the Chinese hukou system. On the other hand, the rise of Shenzhen as one of the two major economic centers in the urban system of Guangdong is related to the rapid economic growth of the city. Preliminary results of the paper show that the high level of urbanization in the PRD region is associated with its advanced economy in contrast with non-PRD region in Guangdong province. Similarly, correlation analysis of time-series data shows significant correlation between economic variable and the size of urban built-up area and employment.

Clearly, economic factor plays an important role in the recent expanding urbanization in Guangdong and in China in general. This does not exclude the role of policy and institutional factors but any institutional reforms and policy changes must be based on sound economic foundations. Right institutions and policies will only work in regions and cities with right economic foundations. This is also why the experience of Guangdong cannot be easily repeated elsewhere especially in poor western region of China by introducing the same set of policies and institutions.

\section{REFERENCES}

[1] Shen J. Understanding dual-track urbanisation in post-reform China: conceptual framework and empirical analysis. Popu Space Place 2006; 12(6): 497-516.

[2] Shen J. Estimating urbanization levels in Chinese provinces in 1982-2000. Intl Stat Rev 2006; 74(1): 89-107.

[3] Pannell CW. Recent growth and change in China's urban system. In: Ma LJC, Hanten EW, Eds. Urban Gevelopment in modern China, Boulder, Co: Westview Press 1982; pp. 91-113.

[4] Chang SD. The changing system of Chinese cities. Ann Assoc Am Geog 1976; 66: 398-415.

[5] Chang SD. Distribution of China's city population, 1982. Urban Geog 1986; 7: 370-84.

[6] Fan CC. The temporal and spatial dynamics of city-size distributions in China. Popu Res Policy Rev 1988; 70 123-57.

[7] Fan CC. The vertical and horizontal expansions of China's city system. Urban Geog 1999; 20(6): 493-515.

[8] Hsu ML. The expansion of the Chinese urban system, 1953-1990. Urban Geog 1994; 15: 514-36.

[9] Xu X, Ouyang N, Zhou C. The changing urban system of China: new developments since 1978. Urban Geog 1995; 16: 493-504.

[10] Wei Y. State policy and urban systems: the case of China. J Chinese Geog 1997; 7(1): 1-10.

[11] Xu XQ. Differences in urbanization in China by province. Acta Geog Sinica 1986; 40: 8-21.

[12] Pannell CW, Veeck G. Zhujiang Delta and Sunan: a comparative analysis of regional urban systems and their development. In: $\mathrm{Xu}$ X, Yeh AG, Wen C, Eds. The environment and space development in the Pearl River Delta, Beijing: Academic Books Press 1989; pp. 237-52.

[13] Wong KY, Shen J, Eds. Resource P anagement, Xrbanization and JRvernance in Hong Kong and the Zhujiang Delta. Hong Kong: Chinese University Press 2002.

[14] Yeung YM, Shen J, Eds. The Pan-Pearl River Delta: An emerging regional economy in a globalizing China. Hong Kong: The Chinese University Press 2008. 
[15] Lo CP. Recent spatial restructuring in Zhujiang delta, south China a study of socialist regional-development strategy. Ann Assoc Am Geog 1989; 79 (2): 293-308.

[16] Yeh AGO, Lam KC, Li SM, Wong KY. Spatial development in the Pearl river delta: development issues and research agenda. Asian Geog 1989; 8: 1-9.

[17] Xu XQ, Li SM. China's open door policy and urbanization in the Pearl River Delta region. Intl J Urban Reg Res 1990; 14(1): 49-69.

[18] Johnson GE. The political economy of Chinese urbanization: Guangdong and the Pearl River Delta region. In: Guldin G, Ed, Urbanizing China, Westport, CT: Greenwood Press 1992; pp.185220.

[19] Sit VFS, Yang C. Foreign investment induced exo-urbanisation in the Pearl River Delta, China. Urban Stud 1997; 34(4): 647-77.

[20] Lin GCS. Evolving spatial form of urban-rural interaction in the Pearl River Delta, China. Proff Geog 2001; 53 (1): 56-70.

[21] Li SM. Pearl riversville: a survey of urbanization in the Peral River Delta. In: Cheng JYS, Ed. The Guangdong development model and its challenges, Hong Kong: City University of Hong Kong Press 1998; pp. 81-109.

[22] Yeung YM. The emergence of Pearl river delta's mega urbanregion in a globalizing environment. Occasional Paper No. 90. Hong Kong: Hong Kong Institute of Asia-Pacific Studies, The Chinese University of Hong Kong 1999.

[23] Ma LJC, Lin CS. Development of towns in China: a case study of Guangdong Province. Popu Dev Rev 1993; 19(3): 583-606.

[24] Yan XP, Liu X. The mechanism and regulation of rural urbanization in the Pearl River Delta. In: Xu X Q, Sit V F S, Yan X P, Eds. Rural-urban transition and co-ordinated development in China, Beijing: Science Press 1998; pp. 294-301.

[25] Shen J, Feng Z, Wong KY. Dual-track urbanization in a transitional economy: the case of Pearl River Delta in south China. Habitat Intl 2006; 30: 690-705.

[26] Kresl P, Singh B. Competitiveness and the urban economy: Twenty-four large US metropolitan areas. Urban Stud 1999; 36(5/6): 1017-27.

[27] Taylor PJ, Walker DRF. World cities: a first multivariate analysis of their service complexes. Urban Stud 2001; 38(1): 23-47.

[28] Shen J. A study of the temporary population in Chinese cities. Habitat Intl 2002; 26: 363-77.

[29] Mcllwaine C. Third-world development: urbanizing for the future. Prog Hum Geog 1997; 21(3): 406-13.

[30] United Nations. World urbanization prospects: the 1996 revision. New York: United Nations 1998.

[31] Drakakis-Smith D. Third World Cities. London: Routledge 2000.

[32] Puga D. Urbanization patterns: European versus less developed countries. J Reg Sci 1998; 38(2): 231-52.

[33] Trewartha GT. Chinese cities: numbers and distribution. Ann Assoc Am Geog 1951; 41: 331-47.

[34] Chan K. Cities with invisible walls: reinterpreting urbanization in post-1949 China. Hong Kong: Oxford University Press 1994.

[35] McGee TG. The emergence of desakota regions in Asia: expanding a hypothesis. In: Ginsburg N, Koppel B, McGee T G, Eds. The extended metropolis: settlement transition in Asia, Honolulu: University of Hawaii Press 1991; pp. 3-25.

[36] Shen J. Scale, state and the city: urban transformation in post reform China. Habitat Intl 2007; 31(3-4): 303-316.

[37] Oi J. The role of the local state in China's transitional economy. China Quar 1995; 144: 1132-49.

[38] Gu C, Shen J, Wong KY, Zhen F. Regional polarization under the socialist-market system since 1978- a case study of Guangdong province in south China. Env Plan A 2001; 33(1): 97-119.
[39] Yeung YM, Chu DKY, Eds. Guangdong: survey of a province undergoing rapid change. Hong Kong: The Chinese University Press 1998.

[40] Shen J. Urban and regional development in post-reform China: the case of Zhujiang delta. Prog Plan 2002; 57(2): 91-140.

[41] Shen J. Urban growth and sustainable development in shenzhen city 1980-2006, Open Env J 2008; 2: 71-79.

[42] Shen J. Cross-border urban governance in Hong Kong: the role of state in a globalizing city-region. The Prof Geog 2004; 56(4): 53043.

[43] Ma LJC, Cui G. Administrative changes and urban population in China. Ann Assoc Am Geog 1987; 77: 373-95.

[44] Shen J. Rural development and rural to urban migration in China 1978-1990. Geoforum 1995; 26: 395-409.

[45] Zhou Y, Shi Y. Toward establishing the concept of physical urban area in China. ACTA Geog Sinica 1995; 50(4): 289-301.

[46] Zipf GK. Human behaviour and the principle of least effort. Cambridge, MA: Addison Wesley 1949.

[47] Guerin-Pace F. Rank-size distribution and the process of urban growth. Urban Stud 1995; 32(3): 551-62.

[48] Krakover S. Testing the turning-point hypothesis in city-size distribution: the Israeli situation re-examined. Urban Stud 1998; 35(12): 2183-96.

[49] Pumain D. Alternative explanations of hierarchical differentiation in urban systems. In: Pumain D, Ed. Hierarchy in natural and social sciences, Dordrecht: Springer 2006; pp. 169-222.

[50] Batty M. Hierarchy in cities and city systems. In: Pumain D, Ed. Hierarchy in natural and social sciences, Dordrecht: Springer 2006; pp. 143-68.

[51] Sheppard E. City size distribution and spatial economic change. Intl Reg Sci Rev 1982; 7: 127-51.

[52] Brakman S, Garretsen H, van Marrewijk C, van den Berg M. The return of Zipf: towards a further understanding of the rank-size distribution. J Reg Sci 1999; 39(1): 183-213.

[53] Sassen S. Cities in a World Economy. London: Pine Forge Press 2000.

[54] Chan K, Zhang L. The Hukou system and rural-urban migration in China: processes and changes. China Quar 1999; Issue 160: 81855.

[55] National Bureau of Statistics. China urban statistics yearbook 1998. Beijing: China Statistical Publishing House 1999.

[56] Holz CA, Lin Y. Pitfalls of China's industrial statistics: inconsistencies and specification problems. China Rev 2001; 1(1): 29-71.

[57] Guangdong Statistical Bureau. Statistical yearbook of uangdong 1999. Beijing: China Statistical Publishing House 1999.

[58] Guangzhou Yearbook Editorial Board. Guangzhou yearbook 1996. Guangzhou: Guangzhou Yearbook Press 1996.

[59] Nanhai Yearbook Editorial Committee. Nanhai yearbook 1996. Guangzhou: Guangdong People’s Publishing House 1996.

[60] Jiangmen City Statistical Bureau. Statistical yearbook of Jiangmen 1995. Beijing: China Statistical Publishing House 1996.

[61] Shenzhen City Statistical Information Bureau. Statistical yearbook of Shenzhen 1996. Beijing: China Statistical Publishing House 1996.

[62] Guangdong Population Sample Survey Office. National 1\% population sample survey of China 1995 - Guangdong volume. Beijing: China Statistical Publishing House 1996.

[63] Urban socio-economic survey team. Cities of new China over fifty years. Beijing: Xinhua Publishing House 1999.

[64] Shenzhen Planning Bureau. Economic and social development of Shenzhen- reviews and prospects 1998-1999. Shenzhen: Haitian Press 1999.

\section{(C) J. Shen; Licensee Bentham Open.}

This is an open access article distributed under the terms of the Creative Commons Attribution License (http://creativecommons.org/licenses/by/2.5/), which permits unrestrictive use, distribution, and reproduction in any medium, provided the original work is properly cited. 